\title{
SPT3 interacts with TFIID to allow normal transcription in Saccharomyces cerevisiae
}

\author{
David M. Eisenmann, ${ }^{1}$ Karen M. Arndt, Stephanie L. Ricupero, John W. Rooney, ${ }^{2}$ and Fred Winston \\ Department of Genetics, Harvard Medical School, Boston, Massachusetts 02115 USA
}

\begin{abstract}
Mutations in the Saccharomyces cerevisiae gene SPT15, which encodes the TATA-binding protein TFIID, have been shown to cause pleiotropic phenotypes and to lead to changes in transcription in vivo. Here, we report the cloning and analysis of one such mutation, spt15-21, which causes a single-amino-acid substitution in a conserved residue of TFIID. Surprisingly, the spt15-21 mutation does not affect the stability of TFIID, its ability to bind to DNA or to support basal transcription in vitro, or the ability of an upstream activator to function in vivo. To study further the spt15-21 defect, extragenic suppressors of this mutation were isolated and analyzed. All of the extragenic suppressors of spt15-21 are mutations in the previously identified SPT3 gene. Suppression of spt15-21 by these spt 3 mutations is allele-specific, suggesting that TFIID and SPT3 interact and that spt15-21 impairs this interaction in some way. Consistent with these genetic data, coimmunoprecipitation experiments demonstrate that the TFIID and SPT3 proteins are physically associated in yeast extracts. Taken together, these results suggest that SPT3 is a TFIID-associated protein, required for TFIID to function at particular promoters in vivo.
\end{abstract}

[Key Words: Transcription; yeast; TFIID; SPT3; mutants; allele specificity]

Received March 17, 1992; revised version accepted May 21, 1992.

Transcription initiation by RNA polymerase II is a complicated process requiring the formation of a multicomponent, preinitiation complex near the start site of transcription (for review, see Sawadogo and Sentenac 1990; Roeder 1991). This complex is composed of a large number of proteins, including RNA polymerase II and several general transcription factors. These general factors were originally identified by fractionation of HeLa cell nuclear extracts into a number of activities essential for the accurate initiation of transcription by RNA polymerase II in vitro (Matsui et al. 1980; Samuels et al. 1982; Davison et al. 1983). At least some of these general factors have been identified in other eukaryotic systems, including Saccharomyces cerevisiae (Buratowski et al. 1988; Cavallini et al. 1988; Hahn et al. 1989a), Drosophila melanogaster (Wampler et al. 1990), and rat (Conaway and Conaway 1991), indicating that many components of the RNA polymerase II transcription machinery have been evolutionarily conserved.

One of the general factors, TFIID, is believed to begin formation of the preinitiation complex by binding to the TATA box (Sawadogo and Roeder 1985b; Reinberg et al. 1987; Nakajima et al. 1988; Van Dyke et al. 1988; Bura-

Present addresses: ${ }^{1}$ Department of Developmental Biology, Stanford University School of Medicine, Stanford, California 94305 USA; ${ }^{2}$ Department of Biological Chemistry and Molecular Pharmacology, Harvard Medical School, Boston, Massachusetts 02115 USA. towski et al. 1989). Subsequent to TFIID binding, the other general factors and RNA polymerase II assemble in an ordered, stepwise fashion, resulting in the formation of a complete preinitiation complex that can initiate transcription in an ATP-dependent manner (Fire et al. 1984; Van Dyke et al. 1988; Buratowski et al. 1989; Maldonado et al. 1990). In addition to these interactions with other general factors, a number of studies have demonstrated interactions between TFIID and various transcriptional regulatory proteins (for examples, see Sawadogo and Roeder 1985b; Horikoshi et al. 1988; Stringer et al. 1990; Horikoshi et al. 1991; Lee et al. 1991; Workman et al. 1991). Other factors have also been described that form distinct complexes with TFIID on TATA- containing templates and that have effects on transcription in vitro (Meisterernst and Roeder 1991; Meisterernst et al. 1991b). TFIID therefore appears to interact with a surprisingly large number of proteins, in addition to interacting with DNA.

Recently, both Drosophila and human TFIID fractions have been shown to contain the TATA-binding protein (often referred to as TBP; see Pugh and Tjian 1992) in tight association with several other polypeptides referred to as TBP-associated factors or TAFs (Dynlacht et al. 1991; Pugh and Tjian 1991; Tanese et al. 1991). The presence of these associated proteins explains the large difference between the observed molecular mass of TFIID activity in these organisms $(120-750 \mathrm{kD}$; Samuels et al. 
1982; Reinberg et al. 1987; Muhich et al. 1990; Timmers and Sharp 1991) and the known molecular mass of the TATA-binding protein (38 kD; Pugh and Tjian 1992). Some of these associated proteins are apparently required for the interaction of activator proteins with TFIID. Unlike HeLa and Drosophila TFIID, yeast TFIID purifies as a single polypeptide with the same molecular mass as predicted by the sequence of the yeast TFIIDencoding gene (Buratowski et al. 1988; Cavallini et al. 1989; Horikoshi et al. 1989). This result suggests either that yeast TFIID, unlike TFIID from higher eukaryotes, does not associate with other factors or that such factors exist, but their interactions with yeast TFIID are less stable.

We have taken a genetic approach toward the study of TFIID and other transcription factors in S. cerevisiae. Beginning with insertion mutations caused by the retrotransposon $T y$, or its long terminal repeat, $\delta$, which perturb transcription of adjacent genes, a large number of suppressor mutations have been identified that restore normal transcription (for review, see Boeke and Sandmeyer 1991; Winston 1992). These mutations have identified $>17$ SPT (suppressor of $\mathrm{Ty}$ ) genes that appear to play general roles in transcription. One of these genes, SPT15, encodes yeast TFIID (Eisenmann et al. 1989; Hahn et al. 1989b). Mutations in SPT15 and in three other genes, SPT3, SPT7, and SPT8, all lead to a common set of phenotypes, including defects in growth, mating, and sporulation, and the ability to suppress many Ty and solo $\delta$ insertion mutations (Winston et al. 1984a,b, 1987; Eisenmann et al. 1989|. These common phenotypes suggest that the SPT3, SPT7, and SPT8 gene products may be functionally related to TFIID.

Previous work demonstrated that the SPT15 gene is essential for growth and that one mutation, spt15-21, confers several mutant phenotypes and causes alterations in transcription in vivo (Eisenmann et al. 1989). Here, we present further studies on spt15-21 and report that the spt15-21 mutation changes a conserved residue of TFIID. This mutation does not alter the ability of TFIID to bind DNA or to interact with other general factors during transcription initiation. Extragenic suppressors of spt15-21 were isolated and shown to be new mutations clustered in the previously identified gene SPT3. We present both genetic and physical evidence that the SPT3 and TFIID proteins interact physically and suggest that SPT3 is a specificity factor required for transcription initiation at particular promoters.

\section{Results}

The spt15-21 mutation causes an amino acid change in a conserved region of TFIID

Mutations in SPT15 were selected as suppressors of his4$917 \delta$, a solo $\delta$ insertion in the promoter of the HIS 4 gene that causes a $\mathrm{His}^{-}$phenotype (Winston et al. 1987). $\mathrm{Mu}-$ tations in $S P T 15$, such as spt15-21, change this phenotype from $\mathrm{His}^{-}$to $\mathrm{His}^{+}$by altering transcription initiation at this promoter insertion mutation /Eisenmann et al. 1989). Strains that contain spt15-21 have other mutant phenotypes, including poor growth, defects in both mating and sporulation, and reduced levels of wild-type HIS4 transcripts, indicating that the spt15-21 mutation affects transcription at many loci in vivo (Eisenmann et al. 1989).

To determine the change in spt15-21 that causes these mutant phenotypes, the spt15-21 locus was cloned from the genome by the process of gap repair (see Materials and methods). The mutant gene was sequenced, and a single-base-pair change was found in the open reading frame. This change alters codon 174 from GGG to GAG, resulting in the substitution of glutamic acid for glycine (G174E; see Fig. 4B, below). Glycine 174 is a residue in the second of the two conserved repeats of yeast TFIID (Pugh and Tjian 1992), and this glycine residue is conserved in all TFIID sequences determined to date.

\section{The TFID-G174E mutant protein behaves similarly to wild-type TFIID by several assays}

To attempt to determine how the spt15-21 mutation alters TFIID function, the activity of the mutant TFIID protein encoded by spt15-21 (hereafter referred to as TFIID-G174E) was compared with that of wild-type TFIID by several in vitro and in vivo assays. Surprisingly, the mutant and wild-type proteins behaved similarly to each other in every assay.

First, the ability of the purified mutant protein to bind to DNA was tested by using a gel-shift assay. The result shows that the binding of wild-type and mutant TFIID proteins to the adenovirus major late promoter (AdMLP) TATA box region is comparable (Fig. 1A, lanes 2,7). In addition, both proteins form an identical slower mobility complex when partially purified HeLa TFIIA is added, indicating that they both interact similarly with this general factor (Fig. 1A, lanes 3-6,8-11). The same result was obtained by use of a $\delta$-element TATA box and partially purified yeast TFIIA (data not shown). DNase I protection experiments also showed that the two proteins bind to the TATA box in the AdMLP promoter, as well as to two different TATA boxes in the promoter of the insertion mutation his4-912 $\delta$, with similar affinity (data not shown). Therefore, TFIID-G174E is able to bind to DNA and to interact with TFIIA normally in vitro.

Second, the ability of TFIID-G174E to function in an in vitro transcription system was tested, by use of a TFIID-depleted nuclear extract from HeLa cells. The result (Fig. 1B) shows that the mutant protein supports basal transcription as well as wild-type TFIID, suggesting that TFIID-G174E is not impaired in its ability to interact with the other general transcription factors.

Finally, the ability of an acidic transcription activator to function in vivo was compared in yeast strains producing either wild-type TFIID or TFIID-G174E. This experiment was done by measuring the ability of the acidic activator protein GCN4 to stimulate transcription of the wild-type HIS4 gene after amino acid starvation (Hinnebusch 1988). The results (Fig. 1C) show that although the 


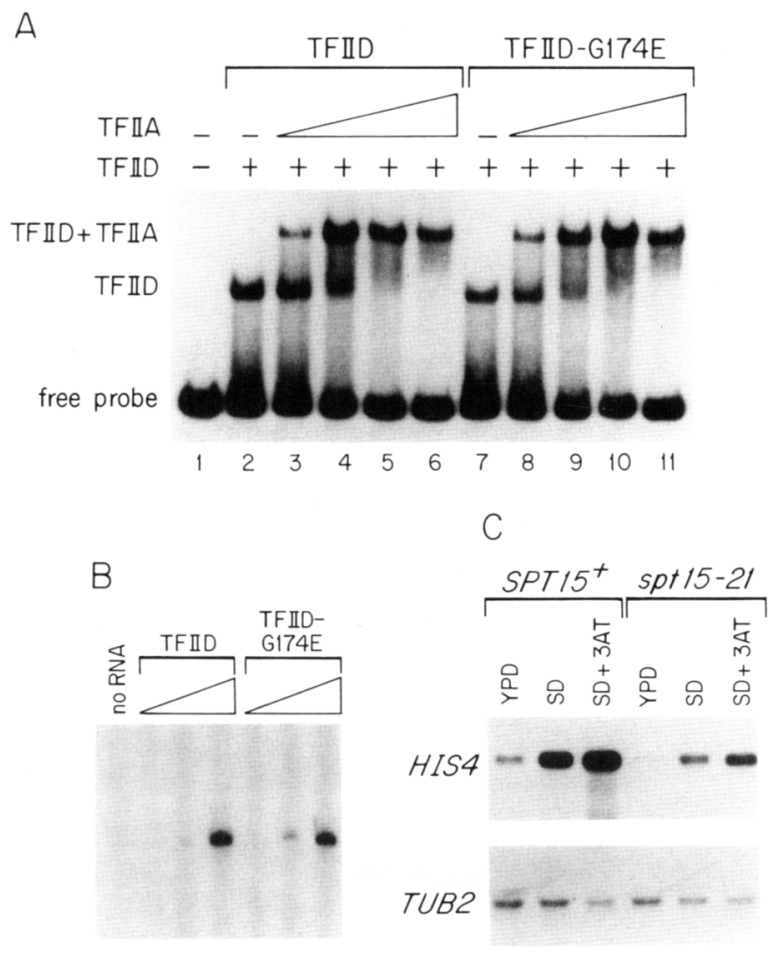

Figure 1. Analysis of TFIID-G174E function. (A) Electrophoretic mobility-shift assay of the interaction of TFIID and TFIIDG174E with the AdMLP TATA box and HeLa TFIIA. A DNA probe containing the AdMLP was incubated with the following proteins under the conditions described in Materials and methods: (Lane 1) No additions; (lanes 2-6) 2 ng of E. coli-produced TFIID; (lanes 7-11) $2 \mathrm{ng}$ of $E$. coli-produced TFIID-G174E; (lanes 3,8 ) $0.21 \mu \mathrm{g}$ of partially purified $\mathrm{HeLa}$ TFIIA; (lanes 4,9) $0.42 \mu \mathrm{g}$ of HeLa TFIIA; (lanes 5,10 ) $0.84 \mu \mathrm{g}$ of HeLa TFIIA; (lanes $6,11) 1.68 \mu \mathrm{g}$ of HeLa TFIIA. (B) In vitro transcription activity of TFIID and TFIID-G174E. In vitro-translated TFIID and TFIIDG174E were added to transcription reactions containing TFIIDdepleted HeLa cell nuclear extract. The G-minus product of the transcription template $\mathrm{pML}\left(\mathrm{C}_{2} \mathrm{AT}\right)_{19} \Delta-50$ (Sawadogo and Roeder 1985a) is shown. In vitro-translated TFIID (lanes 2-4) or TFIID-G174E (lanes 5-7) was added as follows: (lanes 2,5) 0.65

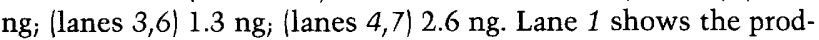
ucts of a control transcription reaction containing $6.5 \mu \mathrm{l}$ of an in vitro translation reaction to which no RNA was added. $(C)$ Northern hybridization analysis of $\mathrm{HIS4}^{+}$transcripts in $S P T 15^{+}$and spt15-21 strains grown under repressing and derepressing conditions. Northern analysis was performed on $4 \mu \mathrm{g}$ of total RNA prepared from SPT15 ${ }^{+}$and spt15-21 strains grown in rich media (YPD), supplemented synthetic media (SD), and supplemented synthetic media containing $10 \mathrm{~mm}$ 3-aminotriazole $(\mathrm{SD}+3 \mathrm{AT})$ as indicated.

absolute level of HIS4 transcripts is decreased in an spt15-21 mutant, the ratio of induced to basal levels of transcription is comparable to that observed in the wildtype strain. Thus, activation by GCN4 is not impaired in a strain producing TFIID-G174E. A second acidic activator, the bovine papillomavirus $\mathrm{E} 2$ protein, which can function in yeast, was also shown to be able to stimulate transcription normally in an spt15-21 strain (J. Benson and P. Howley, pers. comm.). These results indicate that the spt15-21 mutation does not disrupt the ability of acidic activators to stimulate transcription.

Therefore, although the spt15-21 mutation is pleiotropic and results in alterations in transcription in vivo, there is no apparent effect of this mutation on the ability of TFIID to bind to DNA, to interact with other general transcription factors, or to allow stimulation of transcription by acidic activators. We have also observed no effect of the spt15-21 mutation on the level of TFIID in vivo (described in a later section).

\section{Isolation of extragenic and intragenic suppressors of spt 15-21}

To study the defects caused by spt15-21 by a genetic approach, a selection for suppressors was carried out. The selection for spt15-21 suppressors relied on the phenotypes of an spt15-21 strain carrying the insertion mutations his 4-917 $\delta$ and lys2-173R2. An SPT15 ${ }^{+}$strain that contains these insertion mutations is $\mathrm{His}^{-}$and $\mathrm{Lys}^{+}$ (Winston et al. 1984b). The spt15-21 mutation reverses these phenotypes such that an spt15-21 his4-9178 lys2$173 R_{2}$ strain is $\mathrm{His}^{+}$and $\mathrm{Lys}^{-}$(Eisenmann et al. 1989). To isolate suppressors of spt15-21, Lys $^{+}$revertants were selected and then screened for those that had also become His ${ }^{-}$. Forty-eight independent, spontaneous revertants of spt15-21 were isolated and were classified as either strong $\left(\mathrm{His}^{-} \mathrm{Lys}^{+}\right.$) or weak $\left(\mathrm{His}^{-1+} \mathrm{Lys}^{+}\right.$) revertants. Of 48 revertants, 10 were dominant and linked to SPT15 and were assumed to be true revertants; the remaining 38 revertants were recessive.

Four weak revertants were linked tightly to spt15-21, as expected for an intragenic revertant. The mutant spt15 gene was cloned and sequenced from three of these strains (L809, L811, and L812); all three mutant genes still contained the spt15-21 mutation and had also acquired a second mutation. All three intragenic revertants contained a TTT $\rightarrow$ GTT change at codon 237 , resulting in the substitution of valine for phenylalanine (F237V). We assume that this second amino acid change, which does not cause an $\mathrm{Spt}^{-}$phenotype on its own (data not shown), must partially compensate for the effects of the G174E change on TFIID function.

Of the remaining 34 revertants, 23 were shown to be unlinked to spt15-21, demonstrating that they are extragenic. Analysis of progeny from these crosses revealed that 16 of these 23 extragenic suppressors caused a mu-

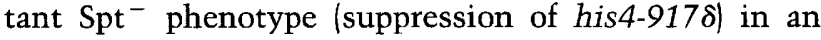
$S P T 15^{+}$background. This phenotype suggested that some of these mutations were in genes functionally related to SPT15.

\section{The extragenic suppressors of spt 15-21 are mutations in SPT3}

Among the large number of SPT genes identified, only mutations in SPT3, SPT7, SPT8, and SPT15 confer suppression of his4-917 $\delta$ /Winston et al. 1987; Eisenmann et al. 1989|. We therefore tested whether the extragenic suppressors of spt15-21 might be alleles of SPT3, SPT7, 
or SPT8. By a combination of complementation tests and linkage analysis, it was determined that, surprisingly, all 34 extragenic suppressors of spt15-21 were mutations in SPT3. We refer to these 34 spt 3 mutations as spt $3^{\text {sup }}$ alleles. Of the 34 isolated, 18 were strong suppressors and 16 were weak suppressors, according to the strength of their suppression of spt15-21.

To determine whether the $s p t 3^{\text {sup }}$ mutations suppress spt15-21 by restoring a wild-type transcription pattern, several transcripts affected by spt15-21 were examined in both spt15-21 spt $3^{\text {sup }}$ double mutants and in $s p t 3^{\text {sup }}$ single mutants. In these experiments, four different $s p t 3^{\text {sup }}$ alleles were used: one strong allele, spt3-401, and three weak alleles, spt3-417, spt3-426, and spt3-445. For each case examined, the spt $3^{\text {sup }}$ mutations suppressed the transcriptional defects caused by spt15-21 (Fig. 2).

For his4-917 , previous work demonstrated that spt1521 suppresses this insertion mutation by altering transcription start site selection (Eisenmann et al. 1989; diagramed in Fig. 2A). In $S P T 15^{+} S P T 3^{+}$his 4-917 $\delta$ strains, the his $4-917 \delta$ transcript produced is longer than the wild-type HIS4 mRNA (Fig. 2B, cf. lanes 1 and 2). The presence of translational start and stop codons upstream of the HIS4 open reading frame presumably renders this long transcript nonfunctional, leading to the His ${ }^{-}$phe-

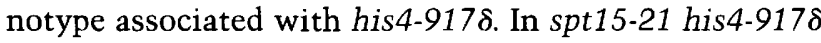
strains, initiation from the wild-type HIS4 transcription start site is restored, resulting in a $\mathrm{His}^{+}$phenotype (Fig. $2 \mathrm{~B}$, lane 4). Analysis of spt15-21 spt $3^{\text {sup }}$ strains shows that the $s p t 3^{\text {sup }}$ mutations reverse the effect of spt15-21 on transcription of his $4-917 \delta$; that is, the pattern of transcripts in spt15-21 spt $3^{\text {sup }}$ double mutant strains resembles that of an $S P T 15^{+} S P T 3^{+}$strain (Fig. 2B, cf. lane 2 with lanes 5-81.

Effects on transcription were also observed in the two other cases examined. First, in an spt15-21 strain, Ty transcripts are much less abundant and are shorter in length than in a wild-type strain (Fig. 2B, cf. lanes 2 and 4). This same alteration has been observed in $\operatorname{spt} 3, \operatorname{spt} 7$, and spt 8 strains; and in those cases, it has been shown to be the result of a change at the $5^{\prime}$ end, presumably caused by altered initiation (Winston et al. 1984b, 1987). This defect in Ty transcription caused by spt15-21 is suppressed by the $s p t 3^{\text {sup }}$ alleles (Fig. 2B, lanes 5-8).

Second, the level of transcripts of $M F \alpha 1$, one of the two genes encoding $\alpha$-factor, is greatly decreased in spt15-21 mutants (Fig. 2B, cf. lanes 2 and 4). This transcriptional defect is suppressed in spt15-21 spt $3^{\text {sup }}$ double mutants (Fig. 2B, lanes 5-8). This defect is most likely one cause of the mating defect of spt15-21 strains (Eisenmann et al. 1989). Thus, for the four spt $3^{\text {sup }}$ alleles examined, suppression occurs in each case by a reversal of the effects of spt15-21 on transcription.

spt $3^{\text {sup }}$ mutations do not alter TFIID protein levels

To determine whether spt15-21 or different spt 3 mutations alter TFIID levels, several strains were examined by use of Western immunoblot analysis and anti-TFIID

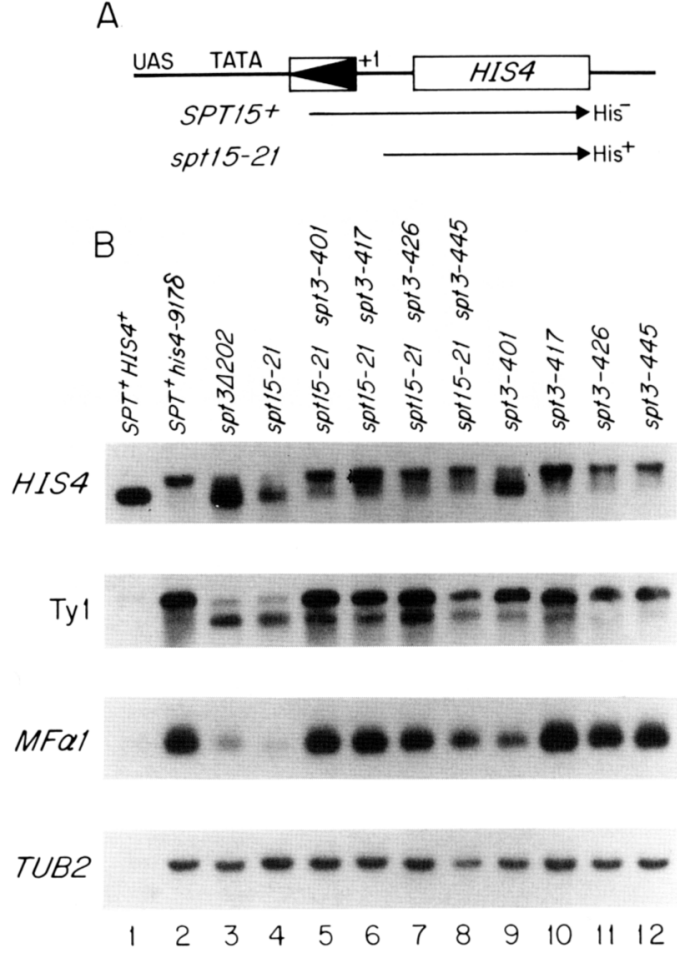

Figure 2. $s p t 3^{\text {sup }}$ mutations suppress the effects of spt15-21 on transcription in vivo. $(A)$ Transcription of his4-917 in SPT15 ${ }^{+}$ and spt15-21 strains. The large open box represents the HIS4coding region; the small box represents the solo $\delta$ inserted $9 \mathrm{bp}$ 5 ' to the normal HIS 4 transcription start site, +1 (not to scale). The arrowhead within the box shows the direction of transcription from the $\delta$ in the context of a complete Ty element. UAS and TATA refer to promoter elements of the HIS4 gene. In an $S P T 15^{+}$strain, a transcript is produced that initiates from a site within the $\delta$ element. This transcript results in a His ${ }^{-}$phenotype. In an spt15-21 mutant, a transcript that initiates from the normal HIS4 start site is made (Eisenmann et al. 1989). (B) Northern hybridization analysis of transcripts in spt15-21 and spt15-21 spt3 ${ }^{\text {sup }}$ strains. Total RNA was prepared from the following strains and analyzed by Northern hybridization: (Lane 1) 3618C ( HIS4 $^{+}$); (lane 2) FY167; (lane 3) FY293; (lane 4) FY255; (lane 5) L805; (lane 6) FY583; (lane 7) FY584; (lane 8) FY585; (lane 9) L806; (lane 10 FY586; (lane 11) FY587; (lane 12) FY588. All strains except $3618 \mathrm{C}$ contain his4-9178. Lane 1 contains 2 $\mu \mathrm{g}$ of total RNA; the remaining lanes contain $12 \mu \mathrm{g}$ of total RNA. Therefore, the $M F \alpha 1$ and TUB2 messages are not detected as well in lane 1 . The same filter was hybridized sequentially with ${ }^{32} \mathrm{P}$-labeled plasmid probes specific for transcripts from HIS4, Ty elements, MF $\alpha 1$, and TUB2.

antisera. Neither spt15-21 nor an spt3 null mutation affects the level of TFIID (Fig. 3, cf. lanes 2, 3, and 4). Likewise, the strong spt $3^{\text {sup }}$ allele spt3-401 shows no obvious effect on TFIID levels in either an $S P T 15^{+}$spt3. 401 strain or in an spt15-21 spt3-401 strain (Fig. 3, lanes $5,6)$. Identical results were observed in strains containing the weak spt $3^{\text {sup }}$ mutations spt3-417, spt3-426, and spt3445 (data not shown). Therefore, the $s p t 3^{\text {sup }}$ mutations do not alter TFIID levels, strongly suggesting that they 


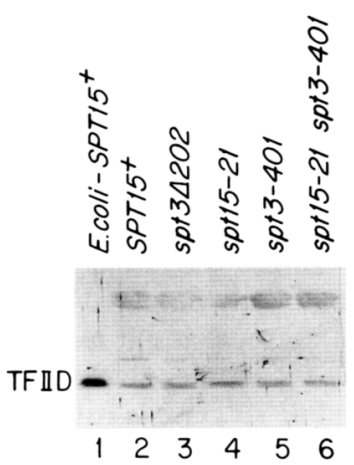

Figure 3. TFIID levels are unaffected by spt15-21 and spt3-401 mutations. Samples of yeast lysates $(12 \mu g$; lanes 2-6), and TFIID purified from $E$. coli (15 $\mathrm{ng}$; lane 1 ), were run on a $12 \%$ polyacrylamide gel, transferred to nitrocellulose, and probed with anti-TFIID antisera. The yeast strains were: FY167 (lane 2); FY293 (lane 3); FY255 (lane 4); L806 (lane 5; and L805 (lane 6). One major and one minor cross-reacting protein from yeast are detected by this antisera.

suppress spt15-21 by compensating for some defective function of the TFIID-G174E protein.

\section{The spt $3^{\text {sup }}$ mutations are clustered}

To determine the sequence changes caused by the spt $3^{\text {sup }}$ mutations, we isolated and sequenced the entire mutant spt 3 gene from each of seven independent spt $3^{\text {sup }}$ mutants: three strong suppressors, spt3-401, spt3-429, and spt3-441; and four weak suppressors, spt3417 , spt3-426, spt3-443, and spt3-445. The results of this analysis (Fig. 4A) show that six of the seven spt $3^{\text {sup }}$ mutations are clustered. First, all three strong spt $3^{\text {sup }}$ mutations, although independent, are the same
GAG $\rightarrow$ AAG change at codon 240 , resulting in a substitution of lysine for glutamic acid (E240K). Second, three weak spt $3^{\text {sup }}$ mutations change the termination codon of the SPT3 gene. Two of these mutations, spt3-426 and spt3-443, are TAA $\rightarrow$ GAA substitutions, which add the amino acids EIFV to the end of the SPT3 protein. The third allele, spt3-417, also alters the stop codon (TAA $\rightarrow$ CAA), adding the residues QIFV to the end of the protein. Finally, the other weak $s p t 3^{\text {sup }}$ mutation, spt3-445, is a change in the amino-terminal region of the $\mathrm{SPT} 3$ protein, AAA $\rightarrow \mathrm{AAT}$, encoding the change $\mathrm{K} 74 \mathrm{~N}$. This clustering of $s p t 3^{\text {sup }}$ mutations in the SPT3 open reading frame suggests that only certain changes in the SPT3 protein can compensate for the TFIID-G174E defect.

\section{Suppression between spt 15 and spt 3 mutations is allele specific}

The clustered sequence changes of the $s p t 3^{\text {sup }}$ alleles suggest that their ability to suppress may be allele specific. To test this idea, we constructed double mutant strains containing different combinations of mutations in SPT15 and SPT3. The results of this analysis (Table 1) demonstrate that suppression is allele specific. First, two other alleles of SPT3, spt3-1 and spt3 $203:: T R P 1$, are not able to suppress spt15-21. Second, spt3-401 and spt3-426, isolated as suppressors of spt15-21, are unable to suppress the $\mathrm{Spt}^{-}$phenotype associated with a different spt15 mutation, spt15-301. These double mutant strains grew more slowly and had more severe $\mathrm{Spt}^{-}$phenotypes than the parent strains. This behavior of different spt15 spt 3 double mutant combinations shows that only certain mutations in these two genes can interact to restore wild-type function and is consistent with the idea that the TFIID and SPT3 proteins directly interact.
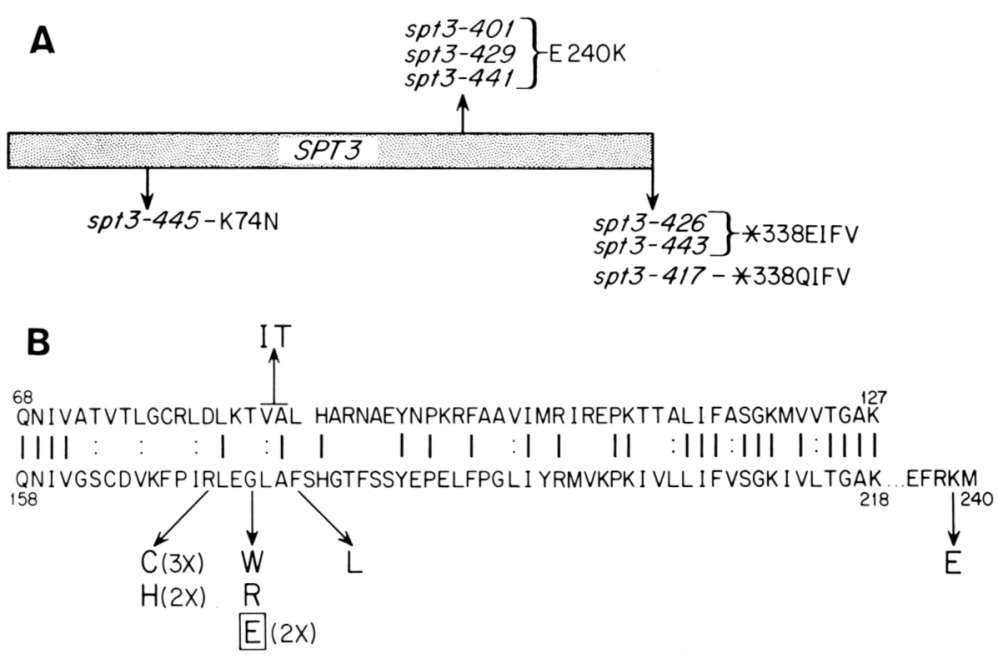

Figure 4. (A) $s p t 3^{\text {sup }}$ mutations are clustered. The box represents the SPT3 protein. The locations and predicted amino acid changes of seven, independent spt $3^{\text {sup }}$ mutations are shown. Those shown above the box are strong suppressors of spt15-21; those below are weaker suppressors. ( $\left.{ }^{*} 338\right)$ The SPT3 stop codon, which is altered by three of these mutations. $(B) \mathrm{Mu}$ tations in SPT15 that suppress spt3-401. Mutations in the SPT15 gene that can suppress the phenotypes of $s p t 3-401$ were isolated and sequenced as described in Materials and methods. Shown are the two repeats of TFIID, aligned with each other. Identical amino acids are indicated by bars; similar amino acids are indicated by colons. The locations and predicted amino acid changes caused by the 12 spt15 mutations are shown. The boxed change, G174E, is the same change that is caused by the spt15-21 mutation. Multiple isolates of the same change are indicated. The mutation found in the first TFIID repeat (top line) is a double mutation causing adjacent amino acid subtitutions (V85I, A86T). When examined in an SPT3 ${ }^{+}$ genetic background, only the mutations affecting residue 174 cause an $\mathrm{Spt}^{-}$phenotype (data not shown). 
Table 1. Allele specificity of the spt15-21 spt3-401 interaction

\begin{tabular}{lll}
\hline Strain & Relevant genotype & Phenotype \\
\hline FY167 & $s P T^{+}$ & wild type \\
FY255 & spt15-21 & mutant \\
L806 & spt3-401 & mutant \\
L805 & spt15-21 spt3-401 & wild type \\
FY810 & spt15-21 spt3s203 & mutant \\
L815 & spt15-21 spt3-1 & mutant \\
L813 & spt15-301 spt3-401 & mutant \\
L814 & spt15-301 spt3-426 & mutant \\
\hline
\end{tabular}

All strains carry the insertion mutation his4-917 . Phenotype refers to the growth of these strains on plates lacking histidine: (Wild type) No growth $\left(\mathrm{Spt}^{+}\right.$phenotype); (mutant) growth $\left(\mathrm{Spt}^{-}\right.$ phenotype).

\section{New spt 15 mutations that suppress spt3-401} are also highly clustered

To investigate the idea that only particular mutations in SPT3 and SPT15 can suppress one another, additional mutations in SPT15 that can suppress spt3-401 were isolated. This was done by mutagenizing the $S P T 15^{+}$gene and then identifying suppressors of spt3-401 by a plasmid shuffle scheme (see Materials and methods). From $\sim 11,000$ transformants, 12 plasmids were found that contained spt15 mutations able to suppress spt3-401. The mutant spt15 genes from these 12 plasmids were sequenced, and the mutations that they contained were found to be highly localized (Fig. 4B). Of the 12 mutations, 10 cause several different amino acid substitutions at positions 171,174 , and 177 in TFIID, including the spt15-21-encoded change, G174E, which was reisolated twice. The eleventh mutation, a double substitution, causes adjacent amino acid changes in the equivalent region of the first repeat of TFIID (V85I,A86T). The twelfth mutation encodes the change K239E at the carboxyl terminus of TFIID; this change is only 2 residues away from the intragenic suppressor of spt15-21 described earlier.

The fact that the majority of mutations are within a stretch of only 7 codons centered around the site of spt15-21 strongly hints at some essential role for this region in an SPT3-TFIID interaction. Taken together with the allele specificity of the spt 15 spt 3 interaction and the clustering of the $\operatorname{spt} 3^{\text {sup }}$ mutations, these data strongly suggest that the TFIID and SPT3 proteins directly interact and that the defect in TFIID-G174E is in its functional or physical interaction with SPT3.

\section{Coimmunoprecipitation of the TFIID and SPT3 proteins}

To test directly whether the SPT3 protein physically interacts with TFIID, we performed coimmunoprecipitation experiments using extracts from yeast strains overexpressing both the TFIID and SPT3 proteins. Previous results showed that SPT3 could only be detected by
Western analysis when produced from a high-copy-number plasmid, suggesting that it is not an abundant protein (Winston and Minehart 1986). To facilitate detection of SPT3, oligo-directed mutagenesis was used to create a gene encoding SPT3 with a 9-amino-acid epitope from the influenza virus hemagglutinin protein $(\mathrm{HAl}$; Niman et al. 1983) at its amino terminus. This tagged protein, HAl-SPT3, is specifically detected by a monoclonal antibody to the HAl epitope, and it migrates on SDS-polyacrylamide gels with a molecular mass of $\sim 43 \mathrm{kD}$ (Fig. 5A). This modified SPT3 gene is fully functional in vivo based on complementation tests (data not shown).

To determine whether HA1-SPT3 was associated with TFIID, coimmunoprecipitation experiments were done as described in Materials and methods. These experiments showed that the HAl-SPT3 protein reproducibly coimmunoprecipitated with wild-type TFIID, indicating that these two proteins are physically associated (Fig. 5B, lane 1). (A low level of TFIID was also precipitated in the absence of anti-TFIID antisera (Fig. 5B, lane 2), probably as a result of a nonspecific interaction of TFIID with the negatively charged resin coupled to our secondary antibody (see Materials and methods). However, consistent with the result found in the presence of the primary antibody, this nonspecific precipitation of TFIID also led to a low level of HAl-SPT3 being coprecipitated (Fig. 5B, lane 2$).]$

Two control experiments were performed to test whether the coimmunoprecipitation of HAl-SPT3 with TFIID indicates a specific interaction between these two proteins. First, we examined whether the amount of HAl-SPT3 that coimmunoprecipitated was dependent on the amount of TFIID present in the yeast extracts. Extracts were prepared from strains overexpressing HAl-SPT3 and either overexpressing or not overexpressing TFIID. Both strains contained the same amount of HA1-SPT3 (Fig. 5C, cf. lanes 1 and 6). From the extract with a high level of TFIID, we saw coimmunoprecipitation of HAl-SPT3 (Fig. 5C, lane 2). However, from the extract with a low level of TFIID, only a very small amount of HA1-SPT3 coimmunoprecipitated, consistent with the decrease in TFID levels (Fig. 5C, lane 4). This result shows that the presence of HAl-SPT3 in the immune complex is dependent on TFIID and is not the result of a nonspecific interaction. Second, HAl- $\beta$-galactosidase was not coimmunoprecipitated with TFIID, demonstrating that the result seen with HA1-SPT3 is specific for SPT3 and is not the result of an interaction caused by the presence of the HAl epitope (Fig. 5D, lane 1). These coimmunoprecipitation experiments, then, support our genetic data and strongly suggest that the wild-type SPT3 and TFIID proteins physically interact in the cell.

Our genetic data are consistent with the idea that the spt15-21 mutation alters the interaction between the TFIID and SPT3 proteins. Conceivably, the spt15-21 mutation could disrupt the physical association of these proteins; alternatively, it could result in a mutant TFIID protein that still interacts physically with SPT3 but has lost a functional interaction between these proteins that 

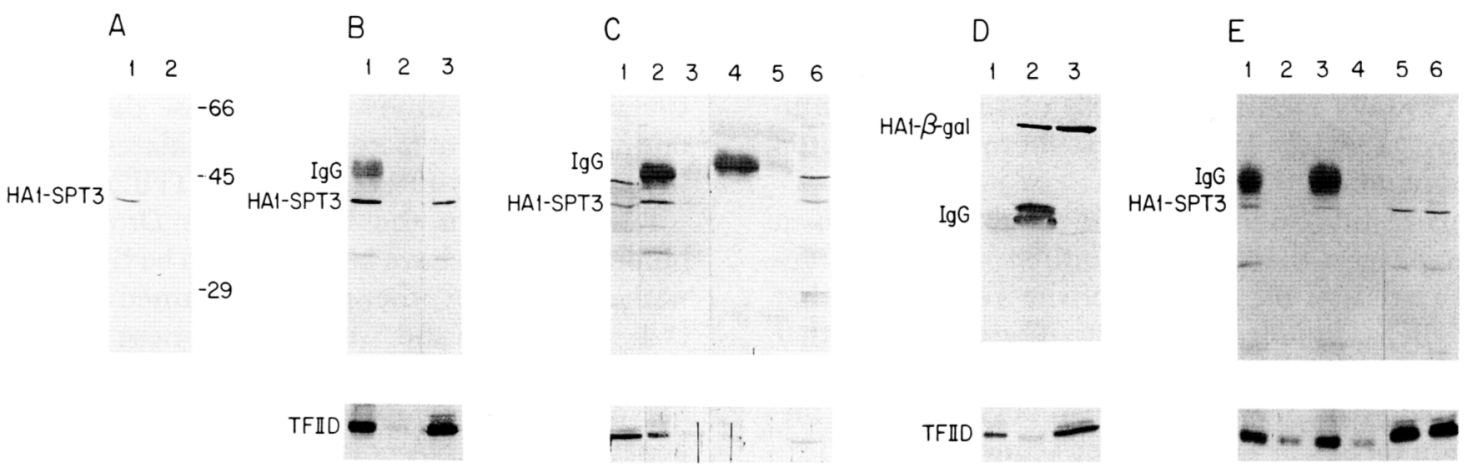

Figure 5. Coimmunoprecipitation analysis of TFIID and SPT3. (A) Identification of the HA1-SPT3 protein. Extracts from strain FY294 containing plasmids encoding HAl-SPT3 (lane 1) or SPT3 (lane 2) were analyzed by Western blotting. The positions of molecular mass markers are shown. $(B-E)$ Coimmunoprecipitation experiments. Extracts were prepared from strain FY294 transformed with high-copy-number plasmids encoding the proteins as listed below. TFIID was immunoprecipitated as described in Materials and methods (+ anti-TFIID Ab), and a duplicate sample was processed to which no anti-TFID antibody was added (- Ab). Each sample was then divided and separated on two $12 \%$ polyacrylamide gels. Proteins were transferred to nitrocellulose and incubated with antibodies to detect the HAl-tagged proteins (top panels) and TFIID (bottom panels). Each panel also shows the amount of each protein in $20 \mu \mathrm{g}$ of total extract (total). (B) FY294 containing high-copy-number plasmids that encode HAl-SPT3 and TFIID. (Lane 1) + anti-TFIID Ab; (lane 2) - Ab; (lane 3) total. (C) FY294 containing high-copy-number plasmids that encode HAl-SPT3 and TFIID. (Lane 1) total; (lane 2) + anti-TFIID Ab; (lane 3) - Ab. FY294 containing only a high-copy-number plasmid encoding HAlSPT3; (lane 4) + anti-TFIID Ab; (lane 5) - Ab; (lane 6) total. These two extracts were done side by side and run on the same gels. To maximize detection of HAl-SPT3, this filter was washed less stringently. (D) FY294 containing high-copy-number plasmids that encode HAl- $\beta$-galactosidase and TFIID. (Lane 1) + anti-TFIID Ab; (lane 2) + anti-HAl Ab; (lane 3) total. (E) Extracts from FY294 containing two different pairs of plasmids were used. (Lanes 1,2,5) FY294 containing high-copy-number plasmids that encode HAlSPT3 and TFIID; (lanes 3,4,6) FY294 containing high-copy-number plasmids that encode HAl-SPT3 and TFIID-G174E. (Lanes 1,3) + anti-TFIID $\mathrm{Ab}$; (lanes 2,4) - $\mathrm{Ab}$; (lanes 5,6 ) total. We estimate that $10-15 \%$ of total TFIID is immunoprecipitated in these experiments and that $5-10 \%$ of the HAl-SPT3 coimmunoprecipitates with TFIID.

is necessary for wild-type activity. To distinguish between these possibilities, we tested whether the TFIIDG174E mutant protein is also able to interact physically with SPT3. Experiments performed as before showed that HA1-SPT3 also coimmunoprecipitated with TFIID-G174E (Fig. 5E, lane 3), indicating that these two proteins do interact. However, we found a variability in the amount of HAl-SPT3 that was coimmunoprecipitated; in some experiments, less HA1-SPT3 was coimmunoprecipitated with TFIID-G174E than with wildtype TFIID (data not shown). This result may indicate that the interaction between SPT3 and TFIID-G174E is less stable than that of the wild-type proteins under these conditions. Nevertheless, coimmunoprecipitation indicates that physical association between these two proteins is not completely abolished by the spt15-21 mutation and is consistent with a model in which the primary defect caused by that mutation is a disruption of a functional interaction between SPT3 and TFIID necessary for wild-type activity.

\section{Discussion}

Mutations in SPT15 and SPT3 were originally identified as suppressors of the transcriptional defects caused by $T y$ and solo $\delta$ insertion mutations in the $5^{\prime}$ region of the yeast HIS4 and LYS2 genes (Winston et al. 1984a, 1987). One mutation in SPT15, spt15-21, causes a number of mutant phenotypes and leads to alterations in transcrip- tion in vivo (Eisenmann et al. 1989). The sequence of the spt15-21 mutation predicts a single-amino-acid substitution (G174E) in a highly conserved region of TFIID. Surprisingly, the mutant product of spt15-21, TFIID-G174E, shows no obvious defect in protein levels, in DNA binding, or in its ability to interact with other general factors in vitro.

To attempt to determine the defect of TFIID-G174E that causes its multiple in vivo phenotypes, intragenic and extragenic suppressors of spt15-21 were isolated and analyzed. All 34 independently isolated, extragenic suppressors of spt15-21 are mutations in SPT3. The stronger of these $s p t 3^{\text {sup }}$ alleles suppress all of the phenotypes associated with spt15-21; and in every case examined, suppression occurs by a reversal of the spt15-21 transcriptional defects. Furthermore, the suppression between spt 15 and spt 3 mutations is allele specific, and these mutations are clustered in each gene. Previous work has shown that allele-specific interactions are strongly indicative of protein-protein interactions (for examples, see Jarvik and Botstein 1975; Adams et al. 1989|. These genetic data therefore strongly suggest that the SPT3 protein and TFID interact directly. In support of this hypothesis, an epitope-tagged SPT3 protein coimmunoprecipitates with TFIID from native yeast extracts. Taken together, these results are consistent with the idea that the SPT3 protein is physically associated with TFIID in vivo and that the primary defect in TFIIDG174E is its inability to interact functionally with wild- 
type SPT3. This model is consistent with previous work that has shown that the phenotypes of an spt 3 null mutant are virtually identical to those of an spt15-21 mutant (Winston et al. 1984b; Hirschhorn and Winston 1988; Eisenmann et al. 1989).

Previous results, along with the results presented in this paper, suggest that SPT3 is required for normal transcription initiation for a subset of the yeast genes that require TFIID. This idea is consistent with the fact that unlike TFIID, SPT3 is not essential for growth. Experiments to date have not suggested an obvious biochemical function for SPT3. The predicted sequence of the 337amino-acid SPT3 protein has no significant similarity to other protein sequences or to characterized functional motifs (Winston and Minehart 1986). Although SPT3 is nuclear localized (C.S. Hoffman and F. Winston, unpubl.), in vitro-synthesized SPT3 has no detectable DNA-binding activity (J. Hirschman and F. Winston, unpubl.). Finally, SPT3 has little ability to activate transcription in vivo when fused to the DNA-binding domain of GAL4 (D.M. Eisenmann and F. Winston, unpubl.). Therefore, it seems unlikely that SPT3 functions as a transcriptional activator protein.

One possible function for SPT3 is as a transcriptional adaptor or coactivator at certain genes, being required for the productive interaction of upstream activator proteins with the preinitiation complex (for review, see Pugh and Tjian 1992). The promoters that are affected in spt $3 \mathrm{mu}$ tants are not known to share a common transcription activator, suggesting that if SPT3 functions in this role, it must be capable of interacting with several different activator proteins. Because two acidic activators function normally in an spt15-21 mutant, SPT3 is unlikely to be an adaptor for that class of transcriptional activator.

We favor a general model in which SPT3 is required for TFIID to function at particular promoters, perhaps by being required for the binding of TFIID to certain TATA boxes or for the interaction of TFIID with other members of the preinitiation complex. One component of this model is that in vivo, all TATA boxes are not equivalent and that other factors besides TFIID, such as SPT3, may be important for promoter recognition. A number of previous observations have also suggested this idea. For example, several studies have shown that different TATA boxes do not function similarly in the context of a given promoter, suggesting that the primary sequence of the TATA box and/or flanking sequences is important (Harbury and Struhl 1989; Simon et al. 1990; Taylor and Kingston 1990; Wefald et al. 1990; Li and Sherman 1991).

Results from our laboratory have shown a difference between the use of TATA boxes in vivo and their binding by TFIID in vitro. In the case of the insertion mutation his4-912 $\delta$, there are two TATA elements, $\sim 200 \mathrm{bp}$ apart. Previous studies have shown that in $S P T^{+}$strains, only the upstream TATA box directs transcription initiation, but that in spt3 null and spt15-21 mutants, the downstream TATA directs transcription initiation (Hirschman et al. 1988; Eisenmann et al. 1989). However, in vitro TFIID binds to both TATA boxes with similar affinity (Arndt et al. 1992). Taken together, these results indicate that TFIID alone may be unable to discriminate in vitro between several TATA sequences that are functionally distinct in vivo. We propose that SPT3 may be one of a number of factors that modulates promoter specificity in vivo by interacting with TFIID.

Recently, both the human and Drosophila TATAbinding proteins have been found to be tightly associated with a number of other proteins, termed TAFs (Dynlacht et al. 1991; Pugh and Tjian 1991; Tanese et al. 1991). Our work suggests that SPT3 may be a yeast counterpart of one of these TAFs. Given the conservation of the components of the RNA polymerase II transcription machinery found to date, it seems likely that yeast TFIID, like its Drosophila and human homologs, is also associated with several other proteins in vivo, in addition to SPT3. Given the differences observed between the biochemical properties of TFIID from S. cerevisiae and from higher eukaryotes, if yeast TFIID is part of a complex, then the biochemical identification of other proteins in this complex may prove to be more difficult than for their Drosophila and human functional counterparts. However, the ability to combine genetic and biochemical approaches in yeast should facilitate the identification and study of such factors. In the case of SPT3, further characterization of its interaction with wild-type and mutant TFIID and with other transcription factors, both in vivo and in vitro, will allow us to begin to test specific models of SPT3 function.

\section{Materials and methods}

Strains, genetic methods, and media

The $S$. cerevisiae strains used (Table 2) are derived from S288C (MAT $\alpha$ gal2) and were constructed in this laboratory by standard methods (Rose et al. 1990), except for strains 3618C (from Gerald Fink, M.I.T., Boston, MA) and 4202-15-3 (from Duane Jenness, University of Massachusetts Medical Ctr., Boston, MA). The spt15 alleles spt15 $101::$ LEU2 and spt15-301 are described in Arndt et al. (1992). The leaky allele spt3-1 and the null alleles spt3-101, spt3 202 , and spt3 $203:: T R P 1$ have been described (Winston et al. 1984a; Winston and Minehart 1986; Happel 1989). Escherichia coli strains $\mathrm{HB} 10 \mathrm{l}$ and TB 1 were used as plasmid hosts (Ausubel et al. 1988). Mating, sporulation, and tetrad analysis were done by standard methods (Rose et al. 1990). Yeast strains were transformed by the lithium acetate procedure (Ito et al. 1983). Rich (YPD), minimal (SD), synthetic complete (SC), and sporulation media were prepared as described in Rose et al.s (1990). Cells that had lost URA3-containing plasmids were isolated on SC media containing 5 'fluoroorotic acid (5'-FOA) (Boeke et al. 1987).

\section{Plasmids}

Plasmids were constructed, maintained, and isolated from $E$. coli by standard methods (Ausubel et al. 1988). DNA modification and restriction enzymes were purchased from New England Biolabs (Beverly, MA) and Boehringer Mannheim Biochemicals (Indianapolis, IN). Plasmid pDE38-9 consists of a 6.6$\mathrm{kb}$ ClaI-ScaI restriction fragment containing SPT15 (Eisenmann et al. 1989) in vector pRS316 (Sikorski and Hieter 1989 ) and was used to clone spt15-21 by gap repair, resulting in plasmid p1259-1. A 2.4-kb EcoRI-BamHI piece from p1259-1 was subcloned into plasmid pRS424 (Sikorski and Hieter 1989) 
Table 2. Yeast strains

\begin{tabular}{|c|c|}
\hline FW1259 & $\begin{array}{l}\text { MAT } \alpha \text { spt15-21 his4-917 } \delta \text { lys2-173R2 trp1 } \Delta 1 \\
\quad \text { ura3-52 }\end{array}$ \\
\hline FY3 & MATa ura3.52 \\
\hline FY167 & 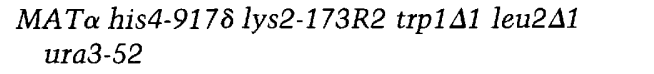 \\
\hline FY255 & 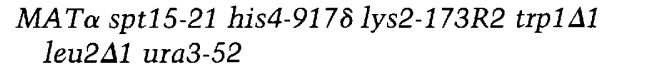 \\
\hline FY293 & 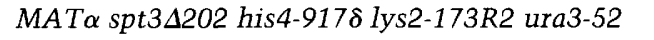 \\
\hline FY294 & $\begin{array}{l}\text { MATa spt3 } \Delta 202 \text { his } 4-917 \delta \text { lys2-173R2 trp } 1 \Delta 63 \\
\text { leu2 } \Delta 1 \text { ura3-52 }\end{array}$ \\
\hline FY567 & $\begin{array}{l}\text { MATa spt15-21 his4-9178 lys2-173R2 leu2 } \Delta 1 \\
\text { ura3-52 ade8 }\end{array}$ \\
\hline FY583 & 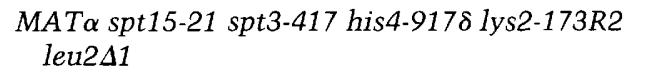 \\
\hline FY584 & 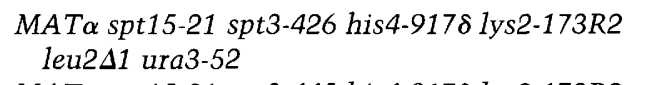 \\
\hline FY585 & $\begin{array}{l}\text { MAT } \alpha \text { spt15-21 spt3-445 his } 4-917 \delta \text { lys2-173R2 } \\
\quad \text { trp1 } 463 \text { ura3-52 }\end{array}$ \\
\hline FY586 & $\begin{array}{l}\text { MAT } \alpha \text { spt3-417 his } 4-917 \delta \text { lys2-173R2 trp1 } \Delta 1 \\
\quad \text { leu2 } \Delta 1\end{array}$ \\
\hline FY587 & 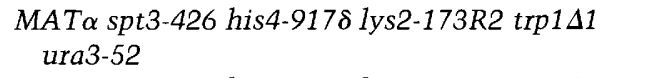 \\
\hline FY588 & 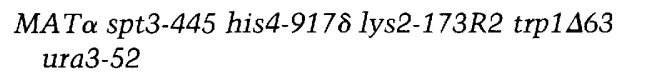 \\
\hline FY647 & 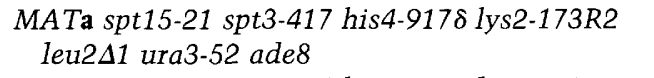 \\
\hline FY648 & 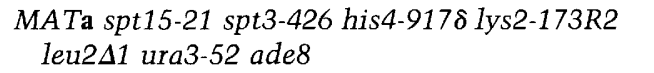 \\
\hline FY649 & 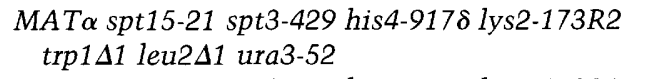 \\
\hline FY650 & 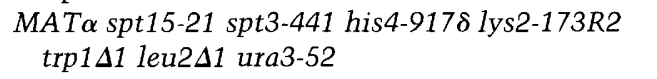 \\
\hline FY651 & 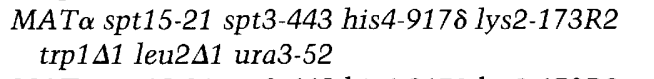 \\
\hline FY652 & 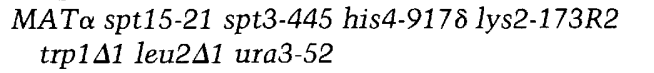 \\
\hline L662 & 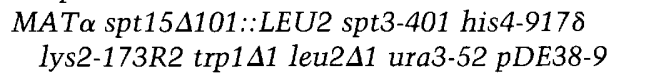 \\
\hline L706 & $M A T \alpha$ spt3-101 his4-917 asp5 \\
\hline L707 & MATa spt3-101 his4-917 $\delta$ asp5 \\
\hline L708 & MAT $\alpha$ spt15-21 his4-917 $\delta$ asp5 \\
\hline L709 & MATa spt15-21 his4-917 $\delta$ asp5 \\
\hline L805 & 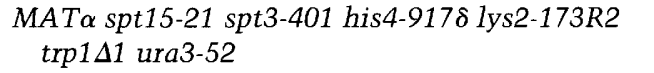 \\
\hline L806 & MAT $\alpha$ spt3-401 his $4-917 \delta$ lys2-173R2 ura3-52 \\
\hline L809 & 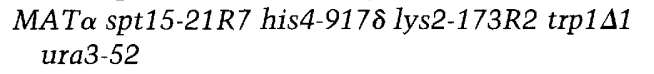 \\
\hline L810 & 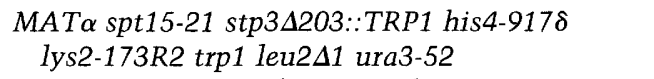 \\
\hline L811 & 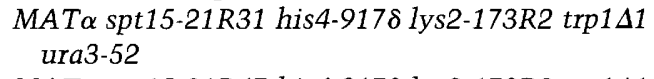 \\
\hline L812 & 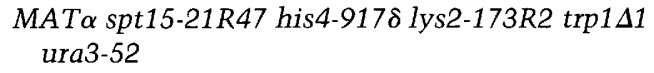 \\
\hline L813 & 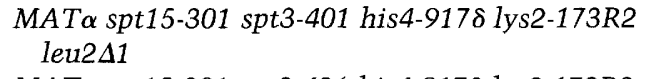 \\
\hline L814 & $\begin{array}{l}\text { MATa spt15-301 spt3-426 his4-9178 lys2-173R2 } \\
\text { ura3-52 leu2 } 11\end{array}$ \\
\hline L815 & $\begin{array}{l}\text { MATa spt15-21 spt3-1 his4-9178 lys2-173R2 } \\
\quad \operatorname{trp} 1 \Delta 1\end{array}$ \\
\hline L861 & $\begin{array}{l}\text { MAT } \alpha \text { spt3-401 his } 4-917 \delta \text { lys2-173R2 leu2 } \Delta 1 \\
\text { ura3-52 }\end{array}$ \\
\hline $3618 \mathrm{C}$ & MAT $\alpha$ his3-532 \\
\hline $4202-15-3$ & $\begin{array}{l}\text { MATa bar1-1 ade2-1 his4-580 lys2 trp1 tyr } \\
\text { SUP4-3(ts) }\end{array}$ \\
\hline
\end{tabular}

to generate plasmid pDE92-6. Plasmids pDE75-2 and pDE93-3 contain the 2.4-kb EcoRI-BamHI piece from pKA12 (Arndt et al. 1992) cloned into the EcoRI and BamHI sites of plasmids pRS314 and pRS426 (Sikorski and Hieter 1989), respectively. To produce TFIID proteins in vitro, the SPT15 and spt15-21 genes were first subjected to oligo-directed mutagenesis (Kunkel et al. 1987; Bio-Rad Laboratories In Vitro Mutagenesis Kit) to introduce a Sall site, which is 24 bp $5^{\prime}$ to the ATG start codon of each gene. The 1164-bp Sall-BamHI fragment containing each gene was subcloned into the SalI-BamHI sites of pSP64 (Promega), generating pKA4 (SPT15) and pKA5 (spt15-21). Plasmids pKA9 and pKAll are derivatives of the T7 expression vector, pET3b (Rosenberg et al. 1987), and were used for expression of the SPT15 and spt15-21 genes in E. coli (Arndt et al. 1992). Plasmid pDE105-6 contains the SPT3 2.6-kb EcoRI-BgIII fragment (Winston et al. 1984) in the EcoRI-BamHI sites of pMR79 (Rose and Fink 1987). This fragment also was subcloned into the EcoRIBamHI sites of M13mpl8 to make pDE106-9. Oligo-directed mutagenesis of pDE106-9 was used to insert sequences into the SPT3 gene that encodes a 9-amino-acid epitope from HAl (Niman et al. 1983) at the $5^{\prime}$ end of SPT3. An EcoRI-HindIII fragment containing this altered gene was inserted into pRS426 to generate pDE119-1. Plasmid pMS35 contains the E. coli lacZ gene fused to sequences encoding the HAl epitope (Swanson et al. 1991).

Isolation and analysis of suppressors of spt15-21

To select for suppressors of spt15-21, 50 cultures each of strains FY255 and FY567 were inoculated with different single colonies and grown to saturation in $2 \mathrm{ml}$ of YPD. These cultures were washed twice in $\mathrm{H}_{2} \mathrm{O}$, diluted in $\mathrm{H}_{2} \mathrm{O}$, and $5 \times 10^{6}$ cells $(0.2 \mathrm{ml})$ of each culture were plated on SC-Lys plates. After several days, all plates contained $\sim 100$ small Lys ${ }^{+}$colonies, and most plates had 1-10 larger $\mathrm{Lys}^{+}$colonies. The larger colonies were regridded on a YPD plate and then replica plated to check their His and Lys phenotypes. Twenty-six independent $\mathrm{His}^{-} \mathrm{Lys}^{+}$revertants were isolated from FY255, and 20 were isolated from FY567. Two additional revertants, spt3-401 and the intragenic spt15-21R7, were isolated separately as spontaneous His ${ }^{-}$Lys $^{+}$ revertants of strain FW1259 after plating on SC-Lys plates. These 48 revertants were categorized as strong ( $\mathrm{His}^{-} \mathrm{Lys}^{+}$) or weak $\left(\mathrm{His}^{-1+} \mathrm{Lys}^{+}\right.$) revertants. All revertants were tested for dominance or recessiveness by mating to spt15-21 lawns and for the presence of $s p t 3$ mutations by complementation tests using spt 3 lawns. Ten dominant revertants and 27 of 38 recessive revertants were crossed to wild-type $\left(S P T^{+}\right)$strains to test for linkage of the new mutation to the SPT15 locus. The progeny were scored with respect to His and Lys phenotypes, and all progeny were tested for complementation of spt15 and spt3 strains. Two cloned and sequenced $s p t 3^{\text {sup }}$ alleles, spt3-401 and spt3-445, were reintegrated into the genome at the SPT3 locus and were shown to confer suppression of spt15-21.

\section{Isolation of suppressors of spt3-401}

Mutations in the SPT15 gene that could suppress spt3-401 were isolated by using the plasmid shuffle technique (Boeke et al. 1987). Plasmid pDE75-2 was mutagenized in vitro with hydroxylamine (Rose et al. 1990). Strain L662 (which contains plasmid pDE38-9) was transformed with the mutagenized pDE75-2 DNA, and $\operatorname{Trp}^{+} \mathrm{Ura}^{+}$transformants were selected. Approximately 11,000 colonies were replica plated to $5^{\prime}$-FOA plates and screened for any that had become $\mathrm{His}^{-}$(indicating suppression of spt3-401); 24 such strains were found. Plasmids from these strains were rescued into E. coli (Hoffman and Winston 1987). 
Retransformation into L662 showed that 12 of the plasmids carried mutations in SPT15 that suppressed spt3-401. These 12 alleles and the correspoding amino acid changes are spt15201(R171C), spt15-202(G174W), spt15-203(G174E), spt15-204 (R171C), spt15-205(V85I,A86T), spt15-206(K239E), spt15-207 (R171C), spt15-208(R171H)， spt15-209(R171H)， spt15-211 (F177L), spt15-212(G174E), and spt15-213(G174R).

\section{Gap repair and DNA sequencing}

To clone the spt15-21 gene by gap repair (Orr-Weaver et al. 1983), plasmid pDE38-9 was digested with EcoRI, deleting a 2.4-kb fragment within the yeast sequences. Strain FW1259 was transformed with this gapped plasmid DNA, and Ura ${ }^{+}$colonies were selected. Plasmids were recovered by transformation of $E$. coli. This method was also used to rescue spt15-21 intragenic revertants from strains L809, L811, and L812. To clone spt3 alleles, plasmid pDE105-6 was digested with MluI and XhoI, deleting a 1.7-kb fragment covering the SPT3 gene. This gapped DNA was transformed into the following strains: L805 (spt3401), FY647 (spt3-417), FY648 (spt3-426), FY649 (spt3-429), FY650 (spt3-441), FY651 (spt3-443), FY652 (spt3-445), and FY167 (SPT3). Plasmid DNA was recovered from these strains into $E$. coli. The complete open reading frame was sequenced on both strands of DNA for all alleles isolated except for spt15-204, spt15-207, and spt15-212. For these genes, $\sim 200$ bp surrounding the base change (on both strands) was sequenced. Both $S P T 15^{+}$ and $S P T 3^{+}$were also cloned by gap repair and sequenced alongside the mutant genes.

\section{Production of TFIID proteins}

Induction of TFIID synthesis in E. coli was done as described (Arndt et al. 1992), except that cells were grown to an $\mathrm{OD}_{600}$ of 1.0. Cells were harvested and washed in two cell-pellet-volumes of buffer A [50 mM Tris-Cl at $\mathrm{pH} 8.0,100 \mathrm{mM} \mathrm{NaCl}, 2 \mathrm{~mm}$ EDTA, $1 \mathrm{~mm}$ dithiothreitol, and $10 \%$ (vol/vol) glycerol]. Cells were lysed by incubation $\left(15 \mathrm{~min}\right.$ at $\left.4^{\circ} \mathrm{C}\right)$ in one cell-pelletvolume of buffer A containing $0.1 \%$ Triton X-100 and $1 \mathrm{~mm}$ phenylmethylsulfonyl fluoride (PMSF), followed by sonication. Extracts were loaded on DEAE-cellulose (Whatmann DE52) columns equilibrated with buffer A containing $1 \mathrm{~mm}$ EDTA and 1 mM PMSF. The pass-through and wash fractions that contained TFIID activity were pooled and dialyzed against buffer $B[20 \mathrm{mM}$ HEPES-KOH at $\mathrm{pH} 7.9,100 \mathrm{~mm} \mathrm{KCl}, 10 \%$ (vol/vol) glycerol, 1 mM EDTA, $1 \mathrm{mM}$ dithiothreitol, and $1 \mathrm{~mm}$ PMSF]. These dialyzed fractions were loaded on S-Sepharose (Pharmacia) columns equilibrated with buffer $B$, and TFIID proteins were eluted with linear gradients of $\mathrm{KCl}(0.1-1.0 \mathrm{M} \mathrm{KCl})$ in buffer B. TFIID and TFIID-G174E eluted at $0.3 \mathrm{M} \mathrm{KCl}$. Estimated purities of the proteins were $25 \%$ for TFIID and $50 \%$ for TFIID-G174E. Relative amounts of TFIID protein in the final fractions were determined by quantitative analysis of Coomassie-stained SDS-polyacrylamide gels and Western blots.

For production of TFIID and TFIID-G174E in vitro, plasmids pKA4 and pKA5 were linearized with $B a m H I$. In vitro transcription and translation reactions were performed essentially as described in Hahn et al. (1989b). In vitro translation products were quantitated by measuring ${ }^{35} \mathrm{~S}$ incorporation and by SDS-polyacrylamide gel electrophoresis.

Electrophoretic mobility-shift and in vitro transcription assays

Bacterially produced TFID ( $2 \mathrm{ng}$ ) and the indicated amounts of partially purified HeLa cell TFIIA were incubated with $\sim 1 \mathrm{ng}$ of
${ }^{32} \mathrm{P}$-labeled AdMLP probe (Buratowski et al. 1989) for $30 \mathrm{~min}$ at $30^{\circ} \mathrm{C}$. HeLa cell TFIIA was purified through the Sephacryl gel filtration column as described previously (Reinberg et al. 1987). Binding reactions and electrophoresis conditions were as described previously (Buratowski et al. 1989), except that $5 \mathrm{~mm}$ $\mathrm{MgCl}_{2}$ was included in the gel and electrophoresis buffer and glycerol was omitted from the gel.

In vitro transcription reactions used the $G$-less cassette assay of Sawadogo and Roeder (1985a) and were done essentially as described (Buratowski et al. 1988) except that $45 \mu \mathrm{g}$ of HeLa cell nuclear extract (Dignam et al. 1983), heat-depleted of endogenous TFIID activity (Nakajima et al. 1988), was used.

\section{Northern hybridization analysis}

Cells for RNA isolation were grown at $30^{\circ} \mathrm{C}$ in supplemented SD media to a density of $1 \times 10^{7}$ to $2 \times 10^{7} \mathrm{cells} / \mathrm{ml}$. For the experiment in Figure 1C, cells were grown in YPD, supplemented SD, and supplemented SD + $10 \mathrm{~mm}$ 3-aminotriazole media. Total RNA was prepared and analyzed as described previously (Swanson et al. 1991). Plasmids used for DNA probes were pFW45 (HIS4; Winston et al. 1984b), pYST138 (TUB2; Som et al. 1988), pHK2 (MFa1; Kurjan and Herskowitz 1982), and pB161 (Ty1; Winston et al. 1984b). RNA levels were normalized based on spectrophotometric measurement, ethidium bromide staining in an agarose gel, and probing filters with a probe for the TUB2 transcript, which is not obviously affected by the mutations studied here.

\section{Coimmunoprecipitation experiments}

Coimmunoprecipitations were done with extracts prepared from strain FY294 transformed with the following pairs of plasmids: (1) pDE119-1 and pDE93-3; (2) pDE1 19-1 and pDE92-6; (3) pDE119-1 and pRS424; and (4) pMS35 and pDE93-3. To prepare protein extracts, cells were grown to $5 \times 10^{7}$ to $6 \times 10^{7}$ cells/ $\mathrm{ml}$, washed twice in lysis buffer $(20 \mathrm{mM}$ HEPES-KOH at $\mathrm{pH} 7.4$, $250 \mathrm{~mm} \mathrm{KAc}, 2 \mathrm{~mm} \mathrm{MgAc}, 2 \mathrm{mM}$ PMSF), transferred to a microcentrifuge tube, and spun down, and the pellets were incubated in a dry ice/ethanol bath for $10 \mathrm{~min}$. Cells were resuspended in $0.25 \mathrm{ml}$ of lysis buffer and broken open by vortexing with glass beads four times for $20 \mathrm{sec}$, with $1 \mathrm{~min}$ on ice between each vortexing. The bottom of each tube was pierced with a hot 19-gauge needle, and the lysate was spun through this hole into another tube by spinning at $2000 \mathrm{rpm}$ for $2 \mathrm{~min}$. The glass beads were then washed with another $0.25 \mathrm{ml}$ of lysis buffer. The combined extract was spun for $10 \mathrm{~min}$ at $14,000 \mathrm{rpm}$, and the supernatant was transferred to a new tube and spun again. Protein concentrations of the supernatant were determined using a Bio-Rad Protein Assay Kit.

For coimmunoprecipitations, $500 \mu \mathrm{g}$ of extract was diluted into immunoprecipitation buffer [(IPB) $50 \mathrm{~mm}$ Tris- $\mathrm{HCl}$ at $\mathrm{pH}$ $7.5,250 \mathrm{~mm} \mathrm{KAc}, 0.1 \%$ Triton X-100, $0.5 \mathrm{mg} / \mathrm{ml}$ of BSA] to a volume of $0.5 \mathrm{ml}$ and incubated at $30^{\circ} \mathrm{C}$ for $30 \mathrm{~min}$. One microliter of anti-yeast TFIID rabbit polyclonal antisera (gift of Steve Buratowski, M.I.T., Boston, MA) was added, and reactions were incubated for $2 \mathrm{hr}$ on a rocking platform at room temperature. Following this incubation, $50 \mu \mathrm{l}$ of secondary antibody was added. The secondary antibody was goat anti-rabbit IgG antibody coupled to agarose beads (Sigma), washed twice in IPB. After a $60-\mathrm{min}$ incubation with rocking at room temperature, immune complexes were collected by spinning at 14,000 rpm for $30 \mathrm{sec}$, washed four times in IPB plus $1 \mathrm{M}$ urea, and resuspended in $23 \mu \mathrm{l}$ of protein sample buffer $(60 \mathrm{~mm}$ Tris- $\mathrm{HCl}$ at $\mathrm{pH}$ $6.8,2 \%$ SDS, $8 \%$ glycerol, $2 \% \beta$-mercaptoethanol, $0.4 \%$ bromophenol blue). Samples were boiled for $3 \mathrm{~min}$, spun in a microcentrifuge at $14,000 \mathrm{rpm}$ for $1 \mathrm{~min}$, and loaded onto two $12 \%$ 
acrylamide gels. Typically, one-quarter of the total immunoprecipitate was loaded on one gel to measure TFIID levels, and the remainder on a second gel to measure HA1-SPT3 levels. We found the interaction between TFIID and SPT3 to vary with temperature and KAc concentration and to be sensitive to the presence of chloride ions (D. Eisenmann and F. Winston, unpubl.). A low level of TFIID was precipitated in experiments done without the addition of primary antisera and is likely the result of the known affinity of TFIID for negatively charged resins (see references in Pugh and Tjian 1992) such as the agarose beads coupled to the secondary antibody, because it was seen with uncoupled beads alone and with TFIID purified from E. coli.

Western blotting was performed as described in Swanson and Winston (1992). For the detection of TFIID, the anti-TFIID antisera was used at a $1: 1000$ dilution. For detection of HAlSPT3 and HAl- $\beta$-galactosidase, ascites fluid containing the anti-HAl epitope mouse monoclonal antibody 12CA5 (Niman et al. 1983) was used at a dilution of $1: 666$. Anti-IgG secondary antibodies coupled to alkaline phosphatase (Promega) were used at a $1: 7500$ dilution.

\section{Acknowledgments}

We are extremely grateful to Steve Buratowski for the gift of anti-TFIID antisera. We thank David Altshuler for helpful discussions, Bob Kingston and Ed Harlow for advice on coimmunoprecipitations, and John Benson and Peter Howley for permission to cite their unpublished data. We also thank David Altshuler, Suzanne Barr, and Greg Prelich for critical reading of the manuscript. This work was supported by grants from the $\mathrm{Na}$ tional Institutes of Health (GM32967 and GM45720), the National Science Foundation (DCB8451649), and the Stroh Brewing Company to F.W. K.M.A. was supported by a postdoctoral fellowship from the Helen Hay Whitney Foundation.

The publication costs of this article were defrayed in part by payment of page charges. This article must therefore be hereby marked "advertisement" in accordance with 18 USC section 1734 solely to indicate this fact.

\section{References}

Adams, A.E., D. Botstein, and D.G. Drubin. 1989. A yeast actinbinding protein is encoded by $S A C 6$, a gene found by suppression of an actin mutation. Science 243: 231-233.

Arndt, K.M., S.L. Ricupero, D.M. Eisenmann, and F. Winston. 1992. Biochemical and genetic characterization of a yeast TFIID mutant that alters transcription in vivo and DNA binding in vitro. Mol. Cell. Biol. 12: 2372-2382.

Ausubel, F.M., R. Brent, R.E. Kingston, D.D. Moore, J.G. Seidman, J.A. Smith, and K. Struhl. 1988. Current protocols in molecular biology. Greene Publishing Associates/Wiley-Interscience, New York.

Boeke, J.D. and S.B. Sandmeyer. 1991. Yeast transposable elements. In The molecular and cellular biology of the yeast Saccharomyces Genome dynamics, protein synthesis, and energetics (ed. J.R. Broach, J.R. Pringle, and E.W. Jones), vol. 1, pp. 193-261. Cold Spring Harbor Laboratory Press, Cold Spring Harbor, New York.

Boeke, J.D., J. Trueheart, G. Natsoulis, and G.R. Fink. 1987. 5-Fluoro-orotic acid as a selective agent in yeast molecular genetics. Methods Enzymol. 154: 164-175.

Buratowski, S., S. Hahn, P.A. Sharp, and L. Guarente. 1988. Function of a yeast TATA element-binding protein in a mammalian transcription system. Nature 334: 37-42.
Buratowski, S., S. Hahn, L. Guarente, and P.A. Sharp. 1989. Five intermediate complexes in transcription initiation by RNA polymerase II. Cell 56: 549-561.

Cavallini, B., J. Huet, J.L. Plassat, A. Sentenac, J.M. Egly, and P. Chambon. 1988. A yeast activity can substitute for the HeLa cell TATA box factor. Nature 334: 77-80.

Cavallini, B., I. Faus, H. Matthes, J.M. Chipoulet, B. Winsor, J.M. Egly, and P. Chambon. 1989. Cloning of the gene encoding the yeast protein BTF1Y, which can substitute for the human TATA box-binding factor. Proc. Natl. Acad. Sci. 86: $9803-9807$.

Conaway, I.W. and R.C. Conaway. 1991. Initiation of eukaryotic messenger RNA synthesis. I. Biol. Chem. 266: 1772117724.

Davison, B.L., J.-M. Egly, E. Mulvihill, and P. Chambon. 1983. Formation of stable preinitiation complexes between eukaryotic class $B$ transcription factors and promoter sequences. Nature 301: 679-686.

Dignam, J.D., R.M. Lebovitz, and R.G. Roeder. 1983. Accurate transcription initiation by RNA polymerase II in a soluble extract from isolated mammalian nuclei. Nucleic Acids Res. 11: 1475-1489.

Dynlacht, B.D., T. Hoey, and R. Tiian. 1991. Isolation of coactivators associated with the TATA-binding protein that mediate transcriptional activation. Cell 66: 563-576.

Eisenmann, D.M., C. Dollard, and F. Winston. 1989. SPT15, the gene encoding the yeast TATA binding factor TFIID, is required for normal transcription initiation in vivo. Cell 58: 1183-1191.

Fire, A., M. Samuels, and P.A. Sharp. 1984. Interactions between RNA polymerase II, factors, and template leading to accurate transcription. J. Biol. Chem. 259: 2509-2516.

Hahn, S., S. Buratowski, P.A. Sharp, and L. Guarente. 1989a. Identification of a yeast protein homologous in function to the mammalian general transcription factor, TFIIA. EMBO $J$. 8: 3379-3382.

Hahn, S., S. Buratowski, P.A. Sharp, and L. Guarente. 1989b. Isolation of the gene encoding the yeast TATA binding protein TFIID: A gene identical to the SPT15 suppressor of Ty element insertions. Cell 58: 1173-1181.

Happel, A.M. 1989. "Analysis of mutations that affect Ty transcription in yeast." Ph.D. thesis, Harvard University, Cambridge, MA.

Harbury, P.A. and K. Struhl. 1989. Functional distinctions between yeast TATA elements. Mol. Cell. Biol. 9: 5298-5304.

Hinnebusch, A.G. 1988. Mechanisms of gene regulation in the general control of amino acid biosynthesis in Saccharomyces cerevisiae. Microbiol. Rev. 52: 248-273.

Hirschhorn, J.N. and F. Winston. 1988. SPT3 is required for normal levels of a-factor and alpha-factor expression in Saccharomyces cerevisiae. Mol. Cell. Biol. 8: 822-827.

Hirschman, J.E., K.J. Durbin, and F. Winston. 1988. Genetic evidence for promoter competition in Saccharomyces cerevisiae. Mol. Cell. Biol. 8: 4608-4615.

Hoffman, C.S. and F. Winston. 1987. A ten-minute DNA preparation from yeast efficiently releases autonomous plasmids for transformation of Escherichia coli. Gene 57: 267-272.

Horikoshi, M., M.F. Carey, H. Kakidani, and R.G. Roeder. 1988. Mechanism of action of a yeast activator: Direct effect of GAL4 derivatives on mammalian TFIID-promoter interactions. Cell 54: 665-669.

Horikoshi, M., C.K. Wang, H. Fujii, J.A. Cromlish, P.A. Weil, and R.G. Roeder. 1989. Purification of a yeast TATA boxbinding protein that exhibits human transcription factor IID activity. Proc. Natl. Acad. Sci. 86: 4843-4847.

Horikoshi, N., K. Maguire, A. Kralli, E. Maldonado, D. Reinberg, 
and R. Weinmann. 1991. Direct interaction between adenovirus E1A protein and the TATA box binding transcription factor IID. Proc. Natl. Acad. Sci. 88: 5124-5128.

Ito, H., K. Fukuda, K. Murata, and A. Kimura. 1983. Transformation of intact yeast cells treated with alkali cations. $J$. Bacteriol. 153: 163-168.

Jarvik, J. and D. Botstein. 1975. Conditional-lethal mutations that suppress genetic defects in morphogenesis by altering structural proteins. Proc. Natl. Acad. Sci. 72: 2738-2742.

Kunkel, T.A., J.D. Roberts, and R.A. Zabour. 1987. Rapid and efficient site-specific mutagenesis without phenotypic selection. Methods Enzymol. 154: 367-382.

Kurjan, J. and I. Herskowitz. 1982. Structure of a yeast pheromone gene (MFalpha): A putative alpha-factor precursor contains four tandem copies of mature alpha-factor. Cell 30: $933-943$.

Lee, W.S., C.C. Kao, G.O. Bryant, X. Liu, and A.J. Berk. 1991. Adenovirus ElA activation domain binds the basic repeat in the TATA box transcription factor. Cell 67: 365-376.

Li, W.Z. and F. Sherman. 1991. Two types of TATA elements for the CYC1 gene of the yeast Saccharomyces cerevisiae. Mol. Cell. Biol. 11: 666-676.

Maldonado, E., I. Ha, P. Cortes, L. Weis, and D. Reinberg. 1990. Factors involved in specific transcription by mammalian RNA polymerase II: Role of transcription factors IIA, IID, and IIB during formation of a transcription-competent complex. Mol. Cell. Biol. 10: 6335-6347.

Matsui, T., J. Segall, P.A. Weil, and R.G. Roeder. 1980. Multiple factors required for accurate initiation of transcription by purified RNA polymerase II. I. Biol. Chem. 255: 1199211996.

Meisterernst, M. and R.G. Roeder. 1991. Family of proteins that interact with TFIID and regulate promoter activity. Cell 67: $557-567$.

Meisterernst, M., A.L. Roy, H.M. Lieu, and R.G. Roeder. 1991. Activation of class II gene transcription by regulatory factors is potentiated by a novel activity. Cell 66: 981-993.

Muhich, M.L., C.T. Iida, M. Horikoshi, R.G. Roeder, and C.S. Parker. 1990. cDNA clone encoding Drosophila transcription factor TFIID. Proc. Natl. Acad. Sci. 87: 9148-9152.

Nakajima, N., M. Horikoshi, and R.G. Roeder. 1988. Factors involved in specific transcription by mammalian RNA polymerase II: Purification, genetic specificity, and TATA boxpromoter interactions of TFIID. Mol. Cell. Biol. 8: 40284040.

Niman, H.L., R.A. Houghtern, L.E. Walker, R.A. Reisfeld, I.A. Wilson, J.M. Hogle, and R.A. Lerner. 1983. Generation of protein-reactive antibodies by short peptides is an event of high frequency: Implication for the structural basis of immune recognition. Proc. Natl. Acad. Sci. 80: 4949-4953.

Orr-Weaver, T.J., J.W. Szostak, and R. Rothstein. 1983. Genetic applications of yeast transformation with linear and gapped plasmids. Methods Enzymol. 101: 228-245.

Pugh, B.F. and R. Tjian. 1991. Transcription from a TATA-less promoter requires a multisubunit TFID complex. Genes \& Dev. 5: 1935-1945.

-1992. Diverse transcriptional functions of the multisubunit eukaryotic TFIID complex. J. Biol. Chem. 267: 679682.

Reinberg, D., M. Horikoshi, and R.G. Roeder. 1987. Factors involved in specific transcription in mammalian RNA polymerase II. Functional analysis of initiation factors IIA and IID and identification of a new factor operating at sequences downstream of the initiation site. J. Biol. Chem. 262: 33223330.

Roeder, R.G. 1991. The complexities of eukaryotic transcrip- tion initiation: Regulation of preinitiation complex assembly. Trends Biochem. Sci. 16: 402-408.

Rose, M.D. and G. Fink. 1987. KAR1, a gene required for function of both intranuclear and extranuclear microtubules in yeast. Cell 48: 1047-1060.

Rose, M.D., F. Winston, and P. Hieter. 1990. Methods in yeast genetics: A laboratory course manual. Cold Spring Harbor Laboratory Press, Cold Spring Harbor, New York.

Rosenberg, A.H., B.N. Lade, D. Chui, S.-W. Lin, J.J. Dunn, and F.W. Studier. 1987. Vectors for selective expression of cloned DNAs by T7 RNA polymerase. Gene 56: 125-135.

Samuels, M., A. Fire, and P.A. Sharp. 1982. Separation and characterization of factors mediating accurate transcription by RNA polymerase II. J. Biol. Chem. 257: 14419-14427.

Sawadogo, M. and R.G. Roeder. 1985a. Factors involved in specific transcription by human RNA polymerase II: Analysis by a rapid and quantitative in vitro assay. Proc. Natl. Acad. Sci. 82: 4394-4398.

- 1985b. Interaction of a gene-specific transcription factor with the adenovirus major late promoter upstream of the TATA box region. Cell 43: 165-175.

Sawadogo, M. and A. Sentenac. 1990. RNA Polymerase B (II) and general transcription factors. Annu. Rev. Biochem. 59: 711754.

Sikorski, R.S. and P. Hieter. 1989. A system of shuttle vectors and yeast host strains designed for efficient manipulation of DNA in Saccharomyces cerevisiae. Genetics 122: 19-27.

Simon, M.C., R.J. Rooney, T.M. Fisch, N. Heintz, and J.R. Nevins. 1990. ElA-dependent trans-activation of the c-fos promoter requires the TATAA sequence. Proc. Natl. Acad. Sci. 87: 513-517.

Som, T., K.A. Armstrong, F.C. Volkert, and J.R. Broach. 1988. Autoregulation of 2 micron circle gene expression provides a model for maintenance of stable plasmid copy levels. Cell 52: $27-37$.

Stringer, K.F., C.J. Ingles, and J. Greenblatt. 1990. Direct and selective binding of an acidic transcriptional activation domain to the TATA-box factor TFIID. Nature 345: 783-786.

Swanson, M.S., E.A. Malone, and F. Winston. 1991. SPT5, an essential gene important for normal transcription in Saccharomyces cerevisiae, encodes an acidic nuclear protein with a carboxy-terminal repeat. Mol. Cell. Biol. 11: 3009-3019.

Swanson, M.S. and F. Winston. 1992. SPT4, SPT5, and SPT6 interactions: Effects on transcription and viability. Genetics (in press).

Tanese, N., B.F. Pugh, and R. Tjian. 1991. Coactivators for a proline-rich activator purified from the multisubunit human TFIID complex. Genes \& Dev. 5: 2212-2224.

Taylor, I.C. and R.E. Kingston. 1990. Ela transactivation of human HSP70 gene promoter substitution mutants is independent of the composition of upstream and TATA elements. Mol. Cell. Biol. 10: 176-183.

Timmers, H.T.M. and P. Sharp. 1991. The mammalian TFIID protein is present in two functionally distinct complexes. Genes \& Dev. 5: 1946-1956.

Van Dyke, D.M.W., R.G. Roeder, and M. Sawadogo. 1988. Physical analysis of transcription preinitiation complex assembly on a class II gene promoter. Science 241: 1335-1338.

Wampler, S.L., C.M. Tyree, and J.T. Kadonaga. 1990. Fractionation of the general RNA polymerase II transcription factors from Drosophila embryos. J. Biol. Chem. 265: 21223-21231.

Wefald, F.C., B.H. Devlin, and R.S. Williams. 1990. Functional heterogeneity of mammalian TATA-box sequences revealed by interaction with a cell-specific enhancer. Nature 344: 260-263.

Winston, F. 1992. Analysis of SPT genes: A genetic approach 
towards analysis of TFIID, histones and other transcription factors of yeast. In Transcriptional regulation led. S.L. McKnight and K.R. Yamamoto). Cold Spring Harbor Laboratory Press, Cold Spring Harbor, New York. (In press.)

Winston, F. and P.L. Minehart. 1986. Analysis of the yeast SPT3 gene and identification of its product, a positive regulator of Ty transcription. Nucleic Acids Res. 14: 6885-6900.

Winston, F., D.T. Chaleff, B. Valent, and G.R. Fink. 1984a. Mutations affecting Ty-mediated expression of the HIS4 gene of Saccharomyces cerevisiae. Genetics 107: 179-197.

Winston, F., K.J. Durbin, and G.R. Fink. 1984b. The SPT3 gene is required for normal transcription of Ty elements in $S$. cerevisiae. Cell 39: 675-682.

Winston, F., C. Dollard, E.A. Malone, J. Clare, J.G. Kapakos, P. Farabaugh, and P.L. Minehart. 1987. Three genes are required for trans-activation of Ty transcription in yeast. $G e$ netics 115: 649-656.

Workman, J.L., I.C. Taylor, and R.E. Kingston. 1991. Activation domains of stably bound GAL4 derivatives alleviate repression of promoters by nucleosomes. Cell 64: 533-544. 


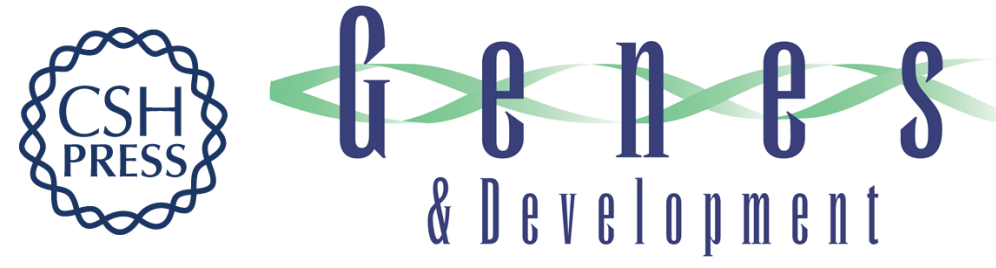

\section{SPT3 interacts with TFIID to allow normal transcription in Saccharomyces cerevisiae.}

D M Eisenmann, K M Arndt, S L Ricupero, et al.

Genes Dev. 1992, 6:

Access the most recent version at doi:10.1101/gad.6.7.1319

References This article cites 63 articles, 34 of which can be accessed free at: http://genesdev.cshlp.org/content/6/7/1319.full.html\#ref-list-1

License

Email Alerting Service right corner of the article or click here.

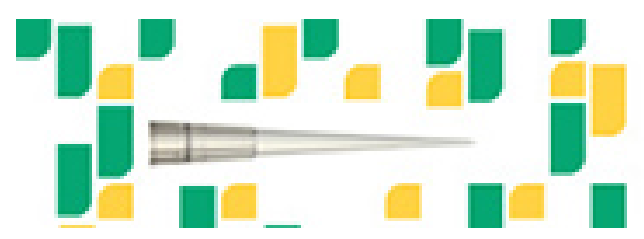

